\title{
EL EFECTO SOFÍSTICO
}

Bárbara CaSSIN

Editorial Fondo de Cultura Económica, Buenos Aress, 2008, 374 Pácinas

ISBN: 9789505577576

E

presente libro corresponde a una obra sugerente sobre las implicancias del movimiento sofístico. Esta palabra movimiento- ha entregado una especial y renovada forma de leer a los sofistas en la actualidad. Los sofistas han sido vapuleados y vituperados de tal manera que la sola palabra sofista condice a una calificación de tipo peyorativo. A este respecto, Bárbara Cassin resalta que la investigación de la sofística condice con un hecho emergente y positivo a la hora de abordar el

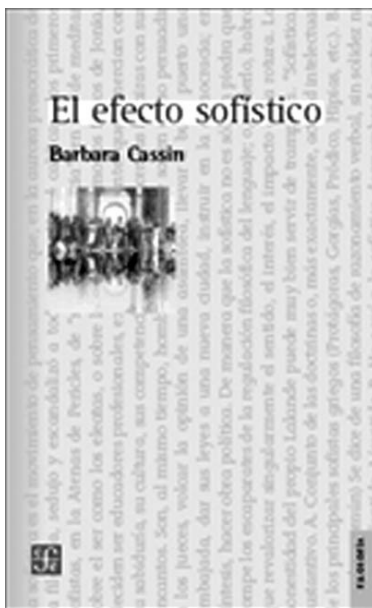
pensamiento sofístico como una reflexión

El efecto sofistico

Barbara Cossin "desde y de" nuestra época. Esta caracterización del pensamiento se encuentra atenta a abordar de manera positiva varios aspectos, entre ellos, el relativismo y el progreso como base en los fenómenos $y$ en el mundo humano, cosa que es propia de un movimiento de tipo humanista. Esta visión, relativamente nueva, da cuenta de la importancia que los sofistas griegos del siglo $\mathrm{V}$ a. $\mathrm{C}$. tuvieron en su época: un movimiento importante dentro de la historia intelectual, pues la sofística es un movimiento de pensamiento que, en la aurora presocrática de la filosofía, cautivó y perturbó a toda Grecia.

La autora aborda el movimiento sofístico en base a tres ejes centrales, a saber: la ontología, la gnoseología y la política. Esta visión se encuentra suscrita a un contexto dado, la democracia ateniense, y, por tal motivo, a una experiencia dada en el lenguaje, pues los sofistas son maestros de la palabra. 
Alfonso Reyes, a propósito de la democracia ateniense, expresa que la importancia de la paideia en la formación del ciudadano es una tarea que le compete a la polis:

El ciudadano acaba de hacerse en la calle, en el mercado, en las discusiones del ágora, en lo que llamaríamos hoy la tertulia de los intelectuales. Los antiguos "symposia" o banquetes orgiásticos que, en las cortes de los tiranos, congregaban a los escogidos en torno a los poetas líricos - por cuya voz se expresaba el sentimiento íntimo de los hombres, sin las preocupaciones políticas que antes dominaban el arte épico y después dominaron el arte trágica- habían venido a ser ahora verdaderas fiestas del espíritu, torneos críticos, indecisas instituciones del buen decir y del pensamiento libre ${ }^{1}$.

Los sofistas disputaban a la poesía ser la educadora de la polis, esto es y tal como Werner Jaeger en su obra monumental Paideia constata, disputaban sobre la formación general del espíritu para la construcción de los ciudadanos, cuyos supuestos apuntan al inmediato telos social. El problema de la educación compete a la política, de esta manera es un asunto propio de la polis. Disputaban a la poesía el uso, belleza, carácter y expresión del lenguaje, trasladando los sofistas el verso al estilo prosaico de sus argumentaciones.

La vinculación con la esfera política podemos traerla a colación por medio de la relación entre Protágoras y Pericles. Protágoras llega a Atenas a mediados del siglo $\mathrm{V}$ y Pericles le confió la redacción del código constitucional para los colonos turios. Protágoras es también autor de la célebre doctrina penal que considera el castigo como una intimidación y corregimiento de la conducta, a diferencia del antiguo códice que implicaba una forma de venganza pública, o mera condenación de tipo religioso.

1 Reyes, A. Junta de sombras. México D. F. 2000.Editorial FCE. P. 192. 
Estos datos no menores vinculan estrechamente a la sofística con la política y, especialmente, con la democracia. A propósito de esto, Hegel expresa el rol de los sofistas de esta manera:

Los sofistas son los maestros de Grecia, y por su intermedio nació en ésta la cultura propiamente dicha. Ellos ocuparon el lugar de los poetas y los rapsodas que eran con anterioridad los maestros universales. (...) La meta del Estado es siempre lo universal, bajo lo cual queda encerrado lo particular; es esa cultura la que los sofistas aspiraron a difundir. La enseñanza era su negocio, su oficio, como una condición que les era propia: sustituían así a las escuelas y, en su incesante recorrido por las ciudades griegas, ganaban la adhesión de la juventud y la instruían².

Hegel define la esencia sofística como una ocupación formadora y cultural, vale decir, aquello que los griegos entendían por paideia, por lo tanto, la sofística y la política son recíprocos.

Bajo estos supuestos la autora rastrea los problemas que conllevan el movimiento sofístico con la filosofía, la relación y conflictos que acaecen en este encuentro, $y$, por último, las lecturas modernas de la sofística.

En una primera instancia, nuestra autora hace un examen a las tesis gorgianas con este sugerente título: "De la ontología a la logología". En este apartado, muy interesante por lo demás, plantea la cuestión del Poema de Parménides y su confrontación con el Tratado de Gorgias. A este respecto, cabe resaltar el título que lleva el tratado y que nos ha llegado gracias a Sexto Empírico, porque es también él quien atribuye a Gorgias su autoría; el título, provocativo por no decir lo menos, es "Sobre el no ser o sobre la Naturaleza". Según Cassin, el título desde ya nos deja en claro un elemento paradigmático: el tratado es una respuesta crítica al Poema de Parménides, y, a su vez, sobre toda la ontología platónico-aristotélica que son la base

\footnotetext{
2 Hegel. Lecciones sobre la historia de la filosofía. En obra citada. P. 104.
} 
de todos los supuestos teóricos de nuestras academias, es decir, la ecuación ontología-verdad.

Desde la semilla plantada por Parménides hasta la cosecha cultivada por Heidegger, designamos por naturaleza a aquello que crece y viene así a la presencia: el ente. El título del tratado gorgiano llama la atención al invertir de manera radical el hablar sobre la naturaleza, puesto que no es, como se cree, hablar del ente sino más bien ocuparse del no ente. Lo que es capaz de crecer es el no ser, apuntando, en estricto rigor, a la famosa tesis de Gorgias: nada es; si es, no se puede conocer; si es y es conocido, no puede comunicarse a los demás. Nuestra autora plantea al respecto:

Después del título y la serie, por último se presenta a su vez cada una de las tres tesis de Gorgias como una inversión irónica o grosera de Parménides escolar que, desde Platón hasta nuestros días, todos hemos debido recordar: en primer lugar, que hay ser, pues el ser es y el no ser no es; a continuación, que ese ser es cognoscible por esencia, porque ser y pensar son una sola y la misma cosa, en virtud de lo cual la filosofía, y más en particular esa filosofía primera que se dio en llamar metafísica, pudo emprender con toda naturalidad su camino: conocer el ser en cuanto ser y efectivizarse en doctrinas, discípulos y escuelas. Ser, conocer, transmitir: no es, no es cognoscible, no es transmisible ${ }^{3}$.

Por lo tanto, pasamos desde un problema ontológico, las esencias, hacia un problema logológico, el decir. El discurso no puede representar lo real y no tiene por qué hacerlo, y, por tal motivo, el discurso es presentado como demiurgo: fabrica el mundo. El discurso hace ser, de esta manera su sentido sólo puede aprehenderse a posteriori, a la luz del mundo producido por él. La ontología de Parménides es aquella en que el discurso vuelve solemne al ser y su tarea es decirlo;

3 Obra citada. P. 28. 
en cambio la logología sofística expresa que el discurso hace ser, es decir, el ser es un efecto del decir.

Otro aspecto que destaca nuestra autora es el hecho de que, en el plano del discurso, la sofística de la Atenas de Pericles desplaza el plano físico de la palabra al plano político. La palabra se instala en la polis. Para este propósito Cassin alude a la problemática que se les atribuye a los sofistas en boca de Platón: los sofistas profesan la doxa, que engaña y se encuentra por doquier en la ciudad. Ser verdadero filósofo es ser, al mismo tiempo, un profesor, debido a que el filósofo-profesor incita a pensar por sí mismo; mientras que el sofista no hace más que contagiar dentro de cada uno las opiniones de todos, impulsando a tomar lo común como lo propio. Esta afirmación plantea que la opinión platónica sobre la ecuación filosofía-educación se manifiesta bajo la imagen de Sócrates como partero; en tanto que los sofistas se encuentran bajo la máscara de la adulación.

No obstante, el encuentro entre filosofía y sofística que nuestra autora vislumbra por antonomasia es el encuentro con Protágoras, porque en él localiza la mayor respuesta a las disquisiciones filosóficas y políticas de Platón. "En efecto, la interpretación que el sofista propone del gran mito político de la sofística (mito de Prometeo) hace intervenir el logos en el logos: aprender la virtud es como aprender a "hablar en griego" (328 a1); ésa es la razón, además, por la que puede creerse que todo el mundo lo enseña o ninguno"4. La explicación que plantea nuestra autora, por un lado, es que lo político no compete a excelencias específicas que deban interpretarse en términos éticos o de moral objetiva, sino más bien es una cuestión autoconstituyente del logos y, por lo tanto, exclusiva de éste. Por otro lado, el tránsito hacia lo político posibilita que el logos sea para los atenienses la toma de la palabra. Los atenienses dejan a cualquier ciudadano tomar la palabra para participar y este es el significado por excelencia de la actividad política en la democracia griega. La ciudad entera enseña a cada uno la virtud a lo largo de su vida y es

4 Obra citada. P. 132. 
también como la virtud puede ser objeto de enseñanza mientras sea compartida por todos.

Las indagaciones que la autora plantea sobre esta cuestión son presentadas como un efecto de la educación que parte desde temprana edad cuando el niño comprende lo que se le dice. Este hecho lleva un planteamiento que es propio de la democracia ateniense: la isegoría, la igualdad que todo ciudadano tiene para expresarse, para hablar, base de la igualdad política en que se plantea que todos tienen y deben asumir su parte en la virtud política, cosa que es orgullo para Atenas.

Esto no quiere decir que no sea posible la existencia de personas destacadas dentro de este clima de igualdad, pues la igualdad ante el derecho a la palabra no implica la igualdad de efecto que produce ésta en los demás. Este hecho nos presenta que sí es posible un sentido de superioridad que estriba en la paideia, vale decir, la superioridad educativa y cultural. Bajo este elemento es necesaria una formación diferenciada y, por lo tanto, quienes tienen los medios hacen impartir una educación diferenciada a sus hijos, planteando, claro está, la existencia de profesores que marcan la diferencia. "Por eso hay maestros y por eso se remunera a Protágoras, quien, cuando desarrolla su discurso, mantiene a Sócrates 'como un enamorado, deseoso de escucharlo'"15.

En síntesis, gracias a los sofistas hubo una oleada inagotable de argumentos ante los ciudadanos de Atenas, entonces, el griego aprende a intercambiar su propio punto de vista, su propia opinión con sus conciudadanos bajo un mismo clima de igualdad. Comienza a considerar el mismo mundo desde la perspectiva de otro griego, pero también esa igualdad no implica necesariamente homogeneidad: "Así, la política es por fuerza política de la apariencia, y la politicidad griega habla el lenguaje de la sofística, que despliega todas sus condiciones de posibilidad: pluralidad, espacio de las apariencias, persuasión y juicio".6.

5 Ibídem. P. 142.

6 Ibídem. P. 188. 
En el plano de la ciudad, el lenguaje, la palabra, cumple un rol importante: el ser de la ontología no es otra cosa más que un efecto del decir. Cosa no menor a la hora de plantear interrogantes sobre la historia de las ideas y poner sobre la mesa un puesto a la sofística en el pensamiento humano. Es un libro riguroso, sistemático y provocador. El lector encontrará interpretaciones de la sofística a partir de lecturas contemporáneas, especialmente, desde el psicoanálisis.

Los primeros y segundos sofistas, Sócrates, Platón, Heidegger, Arendt, Freud, Lacan, entre otros, son traídos en un vaivén hermenéutico que rastrea no solamente la problemática e irrupción de la sofística en la Antigüedad, sino las relaciones, lecturas y repercusiones que ha tenido la sofística -de manera reivindicativa- en nuestra época. Los sofistas son brujos, son adivinos: sus encantos no versan en dar designios ni tampoco interpretar determinados signos; más bien lo son en el sentido en que ponen en juego la fuerza del decir para inducir un nuevo estado y una nueva percepción del mundo.

Rodrigo Escobar San Martín 